\title{
Environment-Friendly Reduction of Aromatics to Alicyclic Compounds at Room Temperature Using Superactive Calcined Ni-Al Hydrotalcite Catalysts
}

\author{
Ateeq Rahman ${ }^{1,}$, Andre Pelletier ${ }^{2}$, Mathew Mupa ${ }^{1}$, Courtie Mahamadi ${ }^{1}$, Cexton Musekiwa ${ }^{1}$ \\ ${ }^{1}$ Department of Chemistry, Bindura University of Science Education, Bindura, Zimbabwe \\ ${ }^{2}$ Department of Chemical Engineer, University of New Brunswick, Fredericton, Canada
}

Email address:

ateeqr786@yahoo.com (A. Rahman)

To cite this article:

Ateeq Rahman, Andre Pelletier, Mathew Mupa, Courtie Mahamadi, Cexton Musekiwa. Environment-Friendly Reduction of Aromatics to Alicyclic Compounds at Room Temperature Using Superactive Calcined Ni-Al Hydrotalcite Catalysts. American Journal of Applied Chemistry. Vol. 4, No. 1, 2016, pp. 18-23. doi: 10.11648/j.ajac.20160401.14

\begin{abstract}
Calcined Ni-Al hydrotalcite (HT) 2: 1, Cat. A, is a superactive catalyst for reduction of substituted aromatics, i. e. toluene, benzene, nitrobenzene, chloro-, bromo-, and iodobenzene to their respective alicyclic products at room temperature in the presence of molecular hydrogen. Cat. A attained higher conversions compared to calcined Ni-Al hydrotalcites with ratios of 2.5: 1, and 3: 1 . Calcined Ni-Al HT is a superactive catalyst whereas catalysts $\mathrm{Ni} \gamma-\mathrm{Al}_{2} \mathrm{O}_{3}$ or $\mathrm{Ni}-\mathrm{SiO}_{2}$ with $\mathrm{Ni}$ contents of $2 \%$, $5 \%$, and $10 \%$ resulted in poor conversions. In these cases, $\mathrm{Ni}$ in association with the respective oxide is the active precursor for molecular hydrogen initiation in the reduction of aromatics to alicyclic compounds. The objective is to evalua4e Ni as the best catalyst for aromatic ring reduction to alicylic molecule. Quantitative yield were obtained for all the substrates toluene, benzene, nitrobenzene, chloro-, bromo-, and iodobenzene to their respective cyclohexanes. These results indicate that hydrogenation with reusable Ni-Al HT catalysts is a green sustainable process and atom economy efficient for the production of various alicyclic compounds.
\end{abstract}

Keywords: Ni-Al Cat A 2: 1 HT, LDHs (Layered Double Hydroxides), Structure, Reduction Reactions

\section{Introduction}

Hydrogen has wide applications in petroleum and chemical industries. With the development of hydrogen fuel cells and strict environmental regulations, energy and transportation applications will contribute to an increasing demand for hydrogen in the near future. This research focuses on the application of hydrogen in an important petrochemical process, specifically the hydro-refining of $\mathrm{C}_{3}$ cut from a thermal cracking unit. Propylene is one of the major building blocks in the petrochemical industry. The majority of propylene is produced as a co-product of the typically contains small amount of methyl acetylene (MA) and propadiene (PD), which must be removed. Industrially, $\mathrm{MA}$ and $\mathrm{PD}$ are removed by selective hydrogenation to propylene, while steam cracking process. The $\mathrm{C}_{3}$ cut obtained from the steam cracking of ethane, propane and naphtha minimizing their over-hydrogenation to propane in a continuous process. Also, new catalysts are always being developed along to support the petrochemical and fine chemicals industries. "Aromatics (e. g. benzene, toluene, and xylene) are produced from two main feed stocks: reformates from catalytic reforming in refineries and steam cracker pyrolysis gasoline. Pyrolysis gasoline is only produced in steam crackers when cracking heavier feed stocks such as naphtha and gas oil. As a result of the dominance of ethane and propane as feedstock for steam cracking, the main source for aromatics in the United States is refinery reformate" [1]. Since many of the aromatics produced in refineries are carcinogenic and separating them is a tedious process, this study aims overcome these obstacles by designing new heterogeneous catalysts for the reduction of aromatics to alicylic compounds which have broad applications in petrochemical and various chemical processes, and in academia [2-6]. Heterogeneous catalytic science has expanded in recent years, and continues to grow, as efforts to make efficient catalyst have resulted in economic benefits through lower cost, recyclability, zero emission of pollutants, and longer catalyst activity lifecycles. Hydrogenation of organic compounds has several applications in the production 
of fine chemicals and in petroleum upgrading. Several catalysts have been used for the reduction of aromatics such as, $\mathrm{Al}_{2} \mathrm{O}_{3}-\mathrm{NaBH}_{4}$ [2, 7], $\mathrm{Cu} / \mathrm{Ru}$ complexes, Raney $\mathrm{Ni}$, $\mathrm{Ni} \gamma / \mathrm{Al}_{2} \mathrm{O}_{3}$ nickel on kieselguhr, cobalt, iron, $\mathrm{Pd}, \mathrm{Pt}, \mathrm{Ru}$, and $\mathrm{Rh}$ [8]. From a theoretical standpoint, addition of hydrogen to an aromatic nucleus is not as easy as is the case with an ethylene or acetylene bond since the energy required to hydrogenate an aromatic compound is very high (in many cases due to resonance stabilization of the compound). The main limitations are the harsh reaction conditions including high temperature, high pressure, sophisticated apparatus, non-reusable/generable catalysts and stoichiometric amounts of reagent's which leads to the formation of copious amounts of undesirable salts, or the need to use pyrophoric catalysts. These catalysts and some of their conditions as follows: $\mathrm{Ru}$ $70-80^{\circ} \mathrm{C} / 60-70 \mathrm{~atm}$, Raney nickel $>100^{\circ} \mathrm{C}, 175^{\circ} \mathrm{C}, 25 \mathrm{Atm}$ $\mathrm{H}_{2}$ Nickel on Keiselguhr [9]. On the other hand, polymer supported phosphine (3) contains triphenyl phosphine $\left(\mathrm{PPh}_{3}\right)$ units which can then be attached to various transition metals, such as rhodium, at temperatures under $100^{\circ} \mathrm{C}$ and pressures of less than 5 atmospheres. However, one limitation is the preparation of phosphine ligands which requires sophisticated apparatus to prepare due to the air sensitive phosphine's. Notably the reactions of benzene or toluene to their respective hydrogenated products were accomplished using this catalyst between $40-50^{\circ} \mathrm{C}$ in $5 \mathrm{H}_{2}$ atm for 80 mins [10]. The reaction was done using noble metal-based catalysts in a two-step process [11-13]. It is recognized that noble metal catalysts present excellent hydrogenation properties at low temperatures, where the thermodynamic limitations are not as severe as those of the metal sulfidetype. However, since this type of catalyst has its own constraints, namely noble metals are known to be easily poisoned by small concentrations of sulfur and nitrogencontaining organic compounds in the feed [10-13] and because of their high cost, they are generally not employed in large-scale commercial processes.

In view of these drawbacks super active heterogeneous catalysts need to be developed that can be reused and are effective under very mild conditions. Hydrotalcites (HTs) have emerged as important catalysts due their valuable applications as anion exchangers, flame retardants and reduction catalysts [14-15]. "HTs are classified as Cationic or Smectite type in which the layered structures are arranged in sheets as brucite type $\mathrm{Mg}(\mathrm{OH})_{2}$ and $\mathrm{Al}(\mathrm{OH})_{2}$ octahedral separated by charge balancing anions, and water both occupy the interlayer spaces. The sheets then stack (in the crystallographic $\mathrm{c}$ direction) to give a characteristic layered material. In many samples of HT, some of the $\mathrm{M}^{2+}$ species are substituted by $\mathrm{M}^{3+}$ species, which results in layers carrying a residual positive charge" [16]. However this charge is balanced by the incorporation of anions between the layers and the anions may be organic or inorganic, with associated water molecules. Morphologically, crystals of HT are micron-sized stacks of hexagonal platelets [14-16]. Thermal calcinations of these materials results in the formation of non-stoichiometric mixed metal-oxides having characteristic properties, which are extremely active catalysts for many important organic transformations including the reduction of aldehydes to alcohols, epoxide ring opening, epoxidation, aldol condensation, transesterification, and Knoevenegal condensation [16-23]. Choudary [18] reported the oxidative bromination of bisphenol-A and excellent activity of Osmate-intercalated HT for asymmetric dihydroxylation of various aliphatic and aromatic olefins using NMO (N-methylmorpholine $\mathrm{N}$-oxide) as co-oxidant [16-25]. Reichle [29] reported intercalation of metallophthallocyanine tetrasulfonate in the intergallery of $\mathrm{Mg}$-Al HT which was synthesized by different routes. The authors' evaluated for first time a convenient method using super active calcined Ni-Al 2: 1 HT (Cat A) for selective reduction of aromatics to alicyclic compounds, e. g. toluene to methyl cyclohexane in mild reaction conditions [16].

\section{Experimental Section}

\subsection{A Typical Experimental Procedure for Reductions}

In a typical experiment, "the catalyst $(0.5 \mathrm{~g})$ was suspended in dry THF $(10 \mathrm{ml})$ and treated with molecular hydrogen for $10 \mathrm{~min}$ and then toluene $(2 \mathrm{mmol})$ was added drop-wise. A hydrogen balloon was fitted to the flask and the resultant solution was stirred at room temperature for $17 \mathrm{hrs}$. The reaction mixture was then subjected to column chromatography (hexane) giving methyl cyclohexane. The product was compared with the standard sample by Shimadzo GC analysis" [15, 30, 35].

\subsection{Preparation of Calcined $\mathrm{Ni}-\mathrm{Al} \mathrm{HT}$ (Ni/Al 2: 1) (Cat A)}

In a typical experiment, "An aqueous solution of $\mathrm{Ni}\left(\mathrm{NO}_{3}\right)_{2} \cdot 6 \mathrm{H}_{2} \mathrm{O}(29.1 \mathrm{~g}, 0.10 \mathrm{~mol})$ and $\mathrm{Al}\left(\mathrm{NO}_{3}\right)_{3} \cdot 9 \mathrm{H}_{2} \mathrm{O}$ $(18.75 \mathrm{~g}, 0.05 \mathrm{~mol})$ in $70 \mathrm{ml}$ distilled water was slowly added to an aqueous solution of $\mathrm{NaOH}(12.0 \mathrm{~g}, 0.3 \mathrm{~mol})$ and $\mathrm{Na}_{2} \mathrm{CO}_{3}(10.0 \mathrm{~g}, 0.094 \mathrm{~mol})$ in $100 \mathrm{ml}$ distilled water under vigorous stirring at room temperature. At the end of $30 \mathrm{~min}$ addition when a milky suspension remained intact, the material was allowed to age at $65^{\circ} \mathrm{C}$ for $18 \mathrm{~h}$. After cooling to room temperature, the solid was filtered, washed with warm distilled water and dried at $125^{\circ} \mathrm{C}$ under vacuum over $\mathrm{P}_{2} \mathrm{O}_{5}$. Ni-Al- $\mathrm{CO}_{3} \mathrm{HT}, \mathrm{Ni} / \mathrm{Al}$ ratios (2.5 and 3) were prepared similarly by taking appropriate ratios of $\mathrm{Ni}$ and $\mathrm{Al}$ nitrates". Then the catalysts were calcined in air for $6 \mathrm{hrs}$ at $450^{\circ} \mathrm{C}$ in furnace then the obtained catalysts is tested for catalytic reactions [16, 30, 35-36].

\subsection{Preparation of Calcined $\mathrm{Ni}$-Al Co-precipitation HT (Ni/Al, 2: 1) (Cat B)}

An aqueous solution of $\mathrm{Ni}\left(\mathrm{NO}_{3}\right)_{2} \cdot 9 \mathrm{H}_{2} \mathrm{O} 29.1 \mathrm{gm} 0.1 \mathrm{~mol}$ and $\mathrm{Al}\left(\mathrm{NO}_{3}\right)_{3} \mathrm{H}_{2} \mathrm{O}$ (18.7 gm, $\left.0.05 \mathrm{~mol}\right)$ in $70 \mathrm{ml}$ distilled water is added to $0.1 \mathrm{M}$ solution of ammonium hydroxide solution drop-wise till completion of precipitation and kept for aging at $65^{\circ} \mathrm{C}$ for about $18 \mathrm{~h}$. The sUV-2600/2700 olid is filtered, washed with warm distilled water and dried under vacuum at $125^{\circ} \mathrm{C} / \mathrm{P}_{2} \mathrm{O}_{5}$ [14-16]. 
UV-Schimadzo 2600/2700, and FT-IR tracer-100 schimadzo is used for characterization of samples.

\section{Results and Discussion}

Table 1. Reduction of toluene to methyl cyclohexane with various $\mathrm{Ni}$ catalysts under same conditions from table 2.

\begin{tabular}{|c|c|c|}
\hline S. No & Catalysts & Conv \% \\
\hline 1. & Ni-Al Cat A 2: 1 calcined & $100 \%$ \\
\hline 2. & Ni-Al Cat A 2.5: 1 calcined & $75 \%$ \\
\hline 3. & Ni-Al Cat A 3: 1 calcined & $63 \%$ \\
\hline 4. & Ni-Al Cat B 2: 1 calcined $\mathrm{NH}_{3}$ & $50 \%$ \\
\hline 5. & Ni-Al Cat A 2: 1 un calcined & No reaction \\
\hline 6. & $\mathrm{Ni} \gamma \mathrm{Al}_{2} \mathrm{O}_{3}$ Cat 2: 1 calcined & No reaction \\
\hline 7. & $\mathrm{Ni}_{\mathrm{Al}} \mathrm{Ol}_{2} \mathrm{O}_{3}$ Cat 5: 1 calcined & No reaction \\
\hline 8. & $\mathrm{Ni} \mathrm{Al}_{2} \mathrm{O}_{3}$ Cat 10: 1 calcined & No reaction \\
\hline 9. & $\mathrm{Ni}-\mathrm{SiO}_{2}-2 \%$ Calcined & No reaction \\
\hline 10. & $\mathrm{Ni}-\mathrm{SiO}_{2}-5 \%$ Calcined & No reaction \\
\hline 11. & $\mathrm{Ni}^{-\mathrm{SiO}_{2}-10 \% \text { Calcined }}$ & No reaction \\
\hline
\end{tabular}

Toluene was reduced to methyl cyclohexane and substituted aromatics were reduced to their respective products in mild conditions with Cat. A and activation of molecular hydrogen was observed at room temperature which resulted in quantitative conversion to respective products. Comparative studies were evaluated using a series of calcined Ni- Al HT with ratios of 2: 1, 2.5: 1, and 3: 1 prepared by the co-precipitation method. Cat A was observed to be a superactive catalysts having excellent activity for the reduction of aromatics. While un-calcined $\mathrm{HT} \mathrm{Ni}-\mathrm{Al}$ 2: 1 didn't exhibit any catalytic activity even under reflux. Cat. B was prepared by the ammonia co-precipitation method and showed moderate activity. In order to obtain a better comparison of these results the authors also investigated $\mathrm{Ni} / \mathrm{\gamma Al}_{2} \mathrm{O}_{3}$ of 2: 1, 5: 1 and 10: 1 calcined prepared by the impregnation method; however, these catalytic preparations did not produce any reactions which indicates that Cat $\mathrm{A}$ is the most suitable catalysts for reduction of toluene to methyl cyclcohexane. The observed order of the specific activity in the reduction of toluene: Cat. A $>\mathrm{Ni}-\mathrm{Al} \mathrm{HT}(2.5: 1)>\mathrm{Ni}-\mathrm{Al}$ HT (3: 1) > Cat. B $>\mathrm{Ni} / \gamma-\mathrm{Al}_{2} \mathrm{O}_{3}(2 \%)>\mathrm{Ni} /{ }_{-}-\mathrm{Al}_{2} \mathrm{O}_{3}(5 \%)>$ $\mathrm{Ni} / \mathrm{Al}_{2} \mathrm{O}_{3}(10 \%)$. An interesting study was examined with $2 \%, 5 \%$, and $10 \% \mathrm{Ni}_{-} \mathrm{SiO}_{2}$ calcined catalysts that resulted in recovery of starting materials. These results confirm that metallic Ni in hydrotalcites is solely responsible for reduction of aromatics to their corresponding products. These results are presented in table 1. As the nickel content increases, the activity decreases due to presence of more nickel particles in the matrices of the HT which causes lower activity observed in samples of $\mathrm{Ni}$ catalysts with ratios of 2.5: 1, and 3: 1 reported by Jonnalgadda et. al [14, 31-37]. In view of these results the authors investigated the reduction of aromatic substrates which have important applications in petrochemical and chemical industries. Reduction of benzene to cyclohexane, nitrobenzene to nitrocyclohexane, chlorobenzene, bromobenzene and iodo benzene to cyclohexanes, conversions using Cat. A is presented in table 2. These results show that nickel HTs are active catalysts for reduction reactions. Cat $\mathrm{A}$ is a non-pyrophoric catalyst, can be used at lower temperatures and pressures which is a reusable, recoverable, screening good atom economy and did not require use of specialized apparatus. This catalyst precludes the wide use of stoichiometric amounts of reagents in these conditions and is applicable to large scale reactions. These reactions are ecofriendly from an environmental point of view, no side products are formed and the reactions, after workup, leads to clean products without disturbing the environment.

Table 2. Represents various aromatic substrates 2.00 mmol reduced in $\mathrm{H}_{2}$ baloon with $\mathrm{Ni}$ Al Cat A 2: 1 Calcined $500 \mathrm{mg}$, room temperature, 17hrs.

\begin{tabular}{llll}
\hline S. No & Substrate & Product & Conv \% \\
\hline 1. & $\mathrm{C}_{6} \mathrm{H}_{5}-\mathrm{CH}_{3}{ }^{\#}$ & $\mathrm{C}_{6} \mathrm{H}_{11}-\mathrm{CH}_{3}$ & $100 \%$ \\
2. & $\mathrm{C}_{6} \mathrm{H}_{5}-\mathrm{NO}_{2}$ & $\mathrm{C}_{6} \mathrm{H}_{11}-\mathrm{NO}_{2}$ & $100 \%$ \\
3. & $\mathrm{C}_{6} \mathrm{H}_{5}-\mathrm{Cl}$ & $\mathrm{C}_{6} \mathrm{H}_{11}-\mathrm{Cl}$ & $85 \%$ \\
4. & $\mathrm{C}_{6} \mathrm{H}_{6}$ & $\mathrm{C}_{6} \mathrm{H}_{12}$ & $100 \%$ \\
5. & $\mathrm{C}_{6} \mathrm{H}_{5}-\mathrm{Br}$ & $\mathrm{C}_{6} \mathrm{H}_{12}$ & $100 \%$ \\
6. & $\mathrm{C}_{6} \mathrm{H}_{5}-\mathrm{I}$ & $\mathrm{C}_{6} \mathrm{H}_{12}$ & $100 \%$ \\
\hline
\end{tabular}

\# means duplicate run.

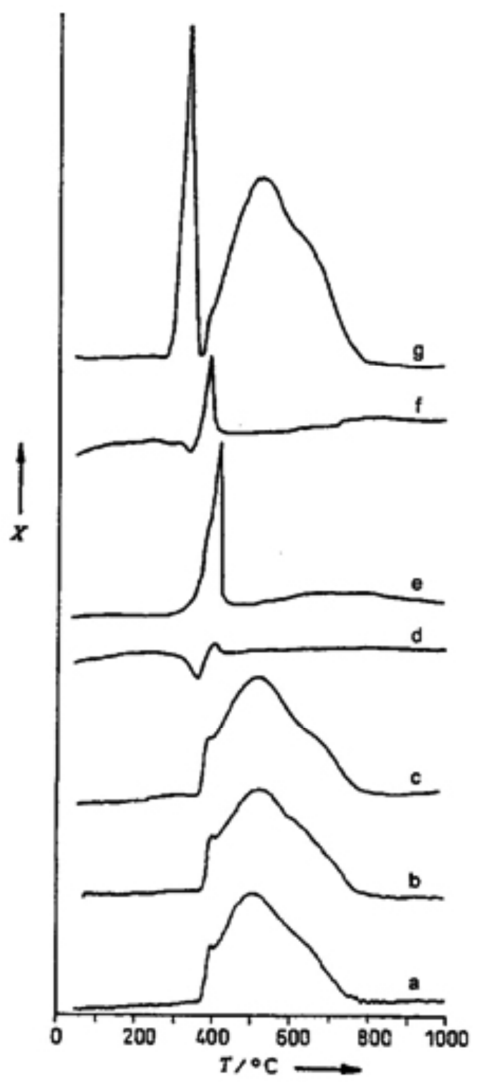

Fig. 1. TPR profiles plotted as amount of hydrogen consumed ( $x$ is arbitrary units) versus temperatures $\left({ }^{\circ} \mathrm{C}\right.$ ) of a) $\mathrm{Ni}$-Al HT (cat A) b) Ni-Al HT (Ni: Al 2.5: 1), c) b) $\mathrm{Ni}-\mathrm{Al} \mathrm{HT}(\mathrm{Ni}: \mathrm{Al} \mathrm{3:1)} \mathrm{d)} \mathrm{Ni}-\gamma$-Al2O3 2\% e) $\mathrm{Ni}-\gamma$-Al2O3 5\% f) $\mathrm{Ni}-\gamma-\mathrm{Al} 2 \mathrm{O} 310 \%$, g) Ni-Al Cat B [36].

\subsection{Catalysts Characterization}

Ni-Al HT 2: 1 catalysts are characterized by TPR, XRD, IR, TEM and UV DRS instruments. 


\subsection{TPR of Ni Hydrotalcite}

The TPR profile of Ni hydotalcite catalysts designates free $\mathrm{NiO}$ is reduced at lower temperatures and $\mathrm{NiO}$ in association with oxide of aluminium is reduced at higher temperatures; whereas ammonia displays both free $\mathrm{NiO}$ and $\mathrm{NiO}$ in association with oxide of aluminium, which is the active species for reduction of aromatics to alicyclic compounds. The free Ni present in Ni-Al HT 2: 1 prepared by the coprecipitation method and the calcined catalysts exhibit activity for reduction of aromatics with all ratios of $\mathrm{Ni}-\mathrm{Al} \mathrm{HT}$ samples $[16,28-31]$. The TPR samples of $\mathrm{Ni} / \gamma-\mathrm{Al}_{2} \mathrm{O}_{3}$ indicate the presence of free $\mathrm{NiO}$. Cat $\mathrm{B}$ prepared using the ammonia method, displays both free $\mathrm{NiO}$ and $\mathrm{NiO}$ in relationship with aluminium oxide [32-36]. The TPR profile of Ni-Al HT prepared by $\mathrm{NaOH} / \mathrm{Na}_{2} \mathrm{CO}_{3}$ exhibited a shoulder at lower temperature which grows on increased free $\mathrm{NiO}$ content, namely from Ni-Al ratio 2: 1, 2.5: 1 and 3: 1 [16, 36]. All these results identify the $\mathrm{Ni}$ in association with aluminium oxide as the active species and major foundation to maximize the activation of molecular hydrogen for reduction of aromatics [1]. The inactivity of the Ni-Al HT 2: 1 uncalcined as-synthesized support the above hypothesis. The excellent results of these catalysts from the characterization studies encouraged the authors to investigate the superactivity of $\mathrm{Ni}$ HT catalysts for the reduction of aromatics to alicylic compounds.

\subsection{XRD of Ni HT}

XRD for Ni HT samples such as carbonates, which have one unit hexagonal cell, have a peak at 11.5 ( $d$ spacing $=7.7$ $\AA)$ and has been attributed to reflections from the (003) family of crystallographic planes. These planes are spaced one-third per unit cell distance apart and correspond to the interlayer distance $[16,29,36]$. The $\mathrm{d}$ spacing is known as the interlayer spacing, which is formed from the metal hydroxide sheet (approximately $4.8 \AA$ ), and the gallery region that contains the intercalated anions is around $2.8 \AA$ in length. The gallery between the metal hydroxide layers is known as the interlayer distance or gallery height. The presence of mixed cubic oxide phases in the calcined samples at $723 \mathrm{~K}$ is obtained by the loss of water and carbon dioxide from the anionic interlayer of HT precursors: Ni-Al 2: 1, 2.5: 1, 3: 1 [16]. HT shows a characteristic crystalline pattern explained above that shows excellent activity for oxidation of alcohols with Ni-Al HT and molecular oxygen reported previously $[16,35]$. The XRD of Cat. A shows the formation of an $\mathrm{NiO}$ phase only with $\mathrm{Al}(\mathrm{III})$ inside, the $\mathrm{NiO}$ particles with suppression of HT pattern [16, 28, 34].

\subsection{Infrared Spectroscopy of Ni HT}

The infrared spectra of HTs display hydroxy stretching vibrations of Cat. A and Ni-Al HT (Ni-Al HT 3: 1). IR, analysis shows fig 2 the foreign bodies of the anions present in the interlayer between the brucite like sheets, also the type of bonds formed by the anion can be obtained by IR. The IR spectra of $\mathrm{MgAlCO}_{3} \mathrm{HT}$, with different $\mathrm{M}$ (II) cations, and
Ni-Al HT, showed an absorption at $3500-3600 \mathrm{~cm}^{-1}$, that has been attributed to the $\mathrm{H}$ bond stretching vibrations of the $\mathrm{OH}$ groups that are present in the brucite like sheets [11]. Generally the shifting of this bond depends upon the $\mathrm{x}$ value for $\operatorname{Mg}(\mathrm{OH})_{2}$. When $\mathrm{X}=0$ the absorption of this band shifts to higher frequency of $3700 \mathrm{~cm}-1$. Cavani et. al. [11, 15, 16, 35] reported that as the $\left(\mathrm{M}^{2+} / \mathrm{M}^{3+}\right)$ ratio increases the hydrogen stretching and bending correlated with the changes in the layer spacing. A shoulder was observed around $3000 \mathrm{~cm}^{-1}$, which has been mainly attributed to hydrogen bonding between $\mathrm{H}_{2} \mathrm{O}$ and the anion in the interlayer [15, 24- 27] while $\mathrm{H}_{2} \mathrm{O}$ bending vibrations occurring at $1600 \mathrm{~cm}^{-1}$. The carbonate anion in an asymmetric environment is characterized by a $\mathrm{D}_{3}$ h planar symmetry, with three IR active absorption bands, as well as in free carbonate anion. In most HTs the three bands appear at $1350-1380 \mathrm{~cm}^{-1}$ (V3), 850-880 $\mathrm{cm}^{-1}$ (V2), and $670-690 \mathrm{~cm}^{-1} \mathrm{~V} 1$. Mostly the intensity of these bands depends upon the type of anion and the amount of $\mathrm{H}_{2} \mathrm{O}$ present in the interlayer of the brucite sheets [36].

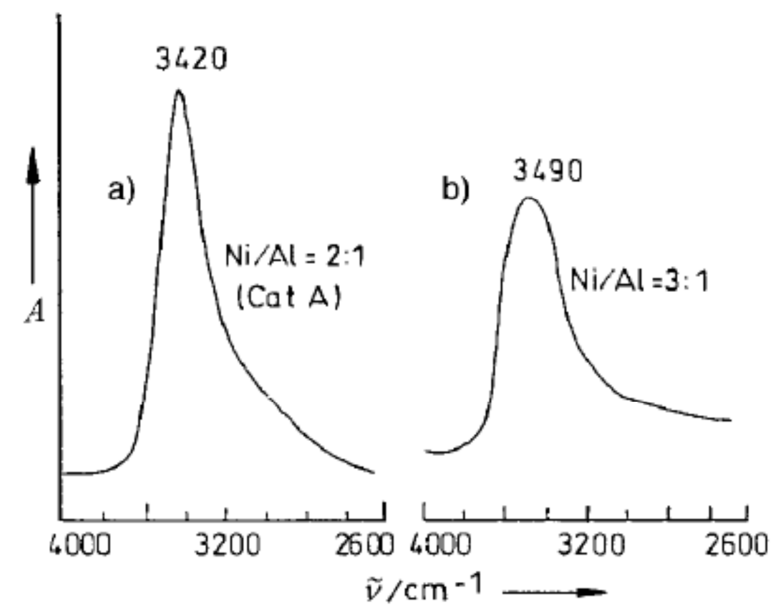

Fig. 2. Hydroxy stretching vibrations of a) Ni-Al hydrotalcite. Cat A (Ni-Al 2: 1 and b) Ni-Al hydrotalcite. Cat B Ni-Al 3: 1 [36].

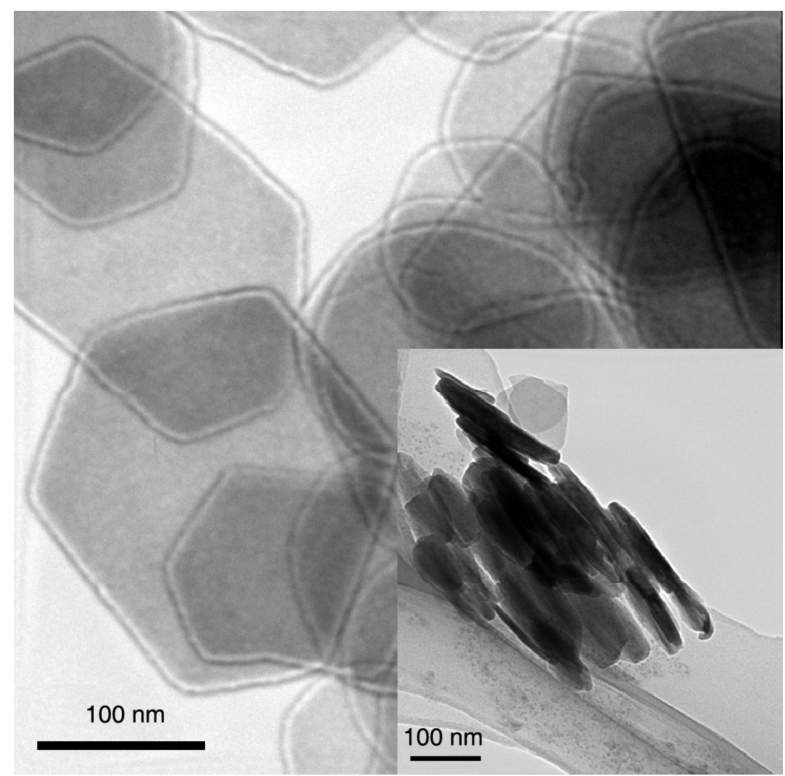

Fig. 3. TEM image of magnetic Ni-Al HTLcs without calcination. 


\subsection{TEM Characterization of Ni HT}

The morphology of a co-precipitated Ni-Al HTs sample without calcination was investigated by TEM. The TEM images are shown in Fig. 3. The flat particle morphology was observed to be regular, and of hexagonal shape throughout [14].

The grain boundaries were well defined and the platelet size was about $200 \mathrm{~nm}$. Dissolution and re-crystallization of the smallest crystallites, along with the amorphous parts, and the parameters applied for the preparation of the catalysts, should be responsible for the large particle size.

\subsection{UV-DRS Spectra of Ni HT}

UV-vis spectra of samples also gives evidences about the re-construction degree since the spectra of transition metal cations are very sensitive to their oxidation state and environment. "A detailed description of the vis-UV spectra of Ni-Al-HTs and derivate oxides is given by Kelkar [24]. $\mathrm{Ni}-\mathrm{Al}$ HTs show three bands around 450, 650 and $1150 \mathrm{~nm}$, with shoulders at ca. 380 and $735 \mathrm{~nm}$. For the mixed oxides, the presence of some $\mathrm{Ni}^{2+}$ ions in tetrahedral holes, together with $\mathrm{Ni}^{2+}$ in octahedral ones, and of $\mathrm{Ni}^{3+}$ species in the oxides obtained by calcination at $550^{\circ} \mathrm{C}$ are responsible for the intense background and intense charge transfer band in the ultraviolet region" [20]. The UV-vis spectra of the microwave-hydrothermally treated samples show that $\mathrm{Ni}$ ions recovered their original location in octahedral holes, and that this relocation is complete after a 300 min treatment [24, 27, 31-45]. Samples of Ni-Al 2.5: 1 HT showed the band at lower wavelength almost disappearing and the broad absorption due to $\mathrm{Ni}^{3+}$ ions is almost negligible; actually, the sample recovered its original green colour. The same behavior is observed for the solids re-constructed at higher temperatures, for Cat A and $\mathrm{Ni}$ Al 2.5: 1 catalysts.

\section{Conclusions}

In conclusion, Cat. A is a superactive catalysts for reduction of aromatics, i. e. toluene to methyl cyclohexane, at room temperature with molecular hydrogen which resulted in high conversion. TPR results indicate that $\mathrm{Ni}$ in association with oxide of alumina is the active species for molecular hydrogen initiation for reduction of aromatics. These results show that nickel HTs are active catalysts for reduction reactions. Cat. A is non-pyrophoric catalysts, high temperatures, pressures reusable, recovery, atom economy, no requirement of specialized apparatus. The catalyst precludes the wide use of stoichiometric amounts of reagents in these conditions and is applicable to large scale reactions. Benzene, bromobenzene, iodobenzene and methyl cyclohexane were reduced to substituted cyclohexanes in quantitative yields. From the above encouraging results the authors further investigated the high catalytic activity in bromination of $\beta$-ketoester at $\alpha$-position the results are being evaluated.

\section{Acknowledgements}

The authors extend their appreciation to the Bindura University of Science Education for supportin this project.

\section{References}

[1] M. Neelis, E. Worrell, E. Masanet. Report, Energy Analysis Department Environmental Energy Technologies Division Ernest Orlando Lawrence Berkeley National Laboratory, (2008) 1-132.

[2] Y. Zhang, S. Liao, Y. Xu, D. Yu Applied Catalysis A 192 (2001) 247-251.

[3] Rossini, Stefano, Catalysis Today, 77, 2003, 467-484.

[4] Al-Khattaf, S. Ph. D Dissertation, University of Western Ontario, London, Ontario, Canada, (2001) 1-33.

[5] Al-Khattaf, S. \& de Lasa, H. Applied Catalysis A General, 2002, 226, 139-153.

[6] Al-Khattaf, S.; Atias, J. A; Jarosch, K.; de Lasa, H. Chemical Engineering Science, (2002), 57, 4909-4920.

[7] J. X. Chen, J. F. Daeuble, D. M. Brestensky, and J. M. Stryker. Tetrahedron, (2000) 2153-2166.

[8] B. Ballarin, and M. Berrettoni et. al.,. Analytica Chemica Acta 538 (2005) 219-224.

[9] Y. Urushibara, Bull. Chem. Soc. Jpn 25, 280, 1952.

[10] Y. Urushibara and Ann. N. Y. Acad. Sci, 145, 52, 1967.

[11] Richard A. Jones, Austin, Tex. U. S. Patent Number: 4,506,030, 1985.

[12] J. Singh, J.; Lamberti, C.; van Bokhoven, J. A. Chem. Soc. Rev. 2010, 39.

[13] J. Barbier, E. Lamy-Pitara, P. Marecot, J. P. Boitiaux, J. Cosyns and F. Verna, Adv. Catal. 37(1) (1992) 41.

[14] P. N. Rylander Catalytic Hydrogenation in Organic Syntheses. 1979, 1 .

[15] F. Cavani and A. Trifiro., et. al, Catalysis. Today 11 (1991) 173-301.

[16] B. M. Choudary, M. L. Kantam, Ateeq Rahman, Ch. V. R. Reddy Journal of Molecular Catalysis A 206 (2003) 145-151.

[17] Ateeq Rahman. International Journal Engineering Sciences \& Emerging Technologies, (2012) 75-82.

[18] B. M. Choudary, M. Lakshmi Kantam., et. al., Tetrahedron Letters., 39 (1998) 3555-3558.

[19] B. M. Choudary, and M. Lakshmi Kantam et. al., Synlett, (1998)1203-1204.

[20] B. M. Choudary, and B. Kavita et. al., Green Chemistry. 1 (1999) 289-292.

[21] B. M. Choudary, and B. Kavita et. al., Tetrahedron, 56 (2000) 9357-9364.

[22] B. M. Choudary, and M. Lakshmi Kantam et. al., Journal of Molecular. Catalysis. A: Chem., 159 (2000) 411-416. 
[23] B. M. Choudary, and T. Someshwar et. Al Applied. Catalysis. Gen A: 251 (2003) 397-409.

[24] B. M. Choudary, N. S. Chowdhari., et. al., Journal. of American. Chemical. Society. 124, (2002) 5341-5349.

[25] C. P. Kelkar. and A. A. Schutz Catalysis Surveys from Asia 10 (1997) 117-137.

[26] M. Lakshmi Kantam, B. Kavita, Ateeq Rahman and M. Sateesh., Indian Journal of Chemistry Sect. B 37 (1998) 10391041.

[27] M. Lakshmi Kantam, and B. M. Chourdary et. al., Chemical Communications. (1998) 1033-1034.

[28] M. Marquevich, and F. Medina et. al., Catalysis Communications 2 (2001) 119-124.

[29] W. T. Reichle, Journal. of Catalysis. 94 (1985) 547-557.

[30] B. d. Rebours et al, Journal of American. Chemical. Society. 116 (1994) 1707-1717.

[31] Ateeq Rahman and S. B. Jonnalagadda, Catalysis. Letters, 123 (2008) 264-266.

[32] Ateeq Rahman and S. B. Jonnalagadda. Journal of Molecular Catalysis A., 299 (2009) 98-101.

[33] V. S. R Rajasekhar Pullabhotla, Ateeq Rahman and S. B. Jonnalagadda Catalysis Communications. 10 (2009) 365-369.

[34] D. Tichit, et. al. Applied. Catalysis. A: 159 (1997) 241-258.

[35] Ateeq Rahman. S. B. Jonnalagadda Synthetic Communications 1, 42 (2012) 1091-1100.
[36] B. M. Choudary, M. Lakshmi Kantam, Ateeq Rahman, K. Koteshwar Rao Angewandte. Chemie. 40 (2001) 763-765.

[37] Ateeq Rahman and S. B. Jonnalagadda Oxidation Communications 36 (2013) 261-270.

[38] Ateeq Rahman, and S. B. Jonnalagadda. Oxidation communications: 35 (2012) 99-109.

[39] Ateeq Rahman and Salem S-Al Deyab Applied Catalysis A: General 469 (2014) 517-523.

[40] Ateeq Rahman, Ilias Ali, Rabeh H Elathy, and Saeed M Al Zahrani NANO 6 (2011) 185-203.

[41] Ateeq Rahman. Bull. Chem. React. Eng. Catal. 5 (2010) 113126.

[42] Tobias Weinert, Simona G Huwiler, Johannes W Kung, Sina Weidenweber, Petra Hellwig, Hans-Joachim Stärk, Till Biskup, Stefan Weber, Julien J H Cotelesage, Graham N George, Ulrich Ermler \& Matthias Boll. Nature Chemical Biology 11 (2015) 586-591 doi: 10.1038/nchembio.1849.

[43] Jafar Mahmoudi, Mohammad Nader Lotfollahi, Ali Haghighi Asl Journal of Industrial and Engineering Chemistry 24 (2015) 113-120.

[44] Georgina C. Laredo, Jesus Castillo, Jose L. Cano. Fuel, 135 (2014) 459-467.

[45] Xuhua Yan, Qi Zhang, Mingqiao Zhu, Zhengbao Wang. Journal of Molecular Catalysis A: Chemical, In Press, Accepted Manuscript, Available online 23 December 2015. 